\title{
LA RENOVACIÓN DE LA FUNCIÓN PARLAMENTARIA DE CONTROL
}

JOSÉ TUDELA ARANDA

Letrado

Cortes de Aragón

SUMARIO

I. Reflexión introductoria. Control, Parlamento y Democracia.

II. La definición del control parlamentario.

III. El Parlamento como receptor de información.

IV. Sobre algunos instrumentos no tradicionales del ejercicio de la función de control y su garantía.

V. La responsabilidad del gobierno en sede parlamentaria.

VI. Fronteras del control parlamentario. Control y nuevas tecnologías.

VII. A modo de conclusión.

\section{REFLEXIÓN INTRODUCTORIA. CONTROL, PARLAMENTO Y DEMOCRACIA}

Son pocos los que hoy niegan que el control es la primera entre las funciones parlamentarias. Y pocos serán los que nieguen que es en su ejercicio donde el Parlamento alcanza mayor notoriedad. Sin embargo, también son pocos los que no denuncian las insuficiencias de esta función, insuficiencias que estarían cerca de desnaturalizarla de raíz. De hecho, son muchos los que ven en su erosión una de las primeras causas de la debilidad del Parlamento contemporáneo. Por ello, en las páginas que siguen se va a realizar un análisis de esta función en relación con algunos cambios sociales y del propio modelo parlamentario, planteando diversas propuestas en aras a su fortalecimiento. 
Pero para pensar en su posible evolución, es necesario realizar alguna consideración preliminar sobre su pasado y presente.

En el Parlamento toma cuerpo la mayoría elegida y el Parlamento elige a aquél que ha de formar Gobierno. De esta manera, la mayoría parlamentaria servirá al Gobierno no sólo facilitando su mantenimiento en el poder sino también legitimando en la Cámara aquellas decisiones del ejecutivo que lo requieran, como las leyes, e, incluso, controlando la labor de la oposición. Es ésta deriva sobre la que hay que llamar la atención. De acuerdo con la situación descrita, fuera de la sesión de investidura, el Parlamento, en circunstancias normales, perderá no ya todo protagonismo, sino incluso buena parte de la razón de ser que debe a las funciones que tiene atribuidas. En esta situación, sus funciones tradicionales sufren una profunda transformación.

Interpretar el Parlamento contemporáneo e intentar adaptarlo a las nuevas exigencias sociales pasa por no ignorar la significación social de la eficacia y de la estabilidad del ejecutivo. Pero tomar estos principios en consideración no significa obviar la necesidad de reivindicar aquellas ideas motrices de la Institución parlamentaria que hoy poseen, al menos, el mismo predicamento social que las citadas de estabilidad y eficacia. La racionalización del modelo democrático, hay que recordarlo, era una manera de introducir garantías en su funcionamiento, garantías indisolublemente unidas al control del poder ejecutivo. Esa idea de garantía y de control es la que sigue simbolizando el Parlamento y la que le dota de su fuerza y vigencia. Porque, en última instancia, el deseo de eficacia no puede sustituir la idea motriz que establece el ser democrático en la legitimidad de la relación establecida entre el pueblo y el poder. Una idea que es forzoso reiterar porque resulta demasiado normal en los últimos años concentrar la legitimidad en la eficacia, en detrimento de cualquier otra consideración ${ }^{1}$.

El Parlamento tiene la responsabilidad de, desde su cultura y en gran medida conservando los valores que la conforman, generar una nueva cultura, una nueva política. Una cultura, una política, no circunscritas a hábitos y costumbres de la Institución. Una nueva cultura que afecte al poder, a su ejercicio y, muy singularmente, a su control. Una cultura que se encuentre adaptada a la realidad emergente. Adaptada a sus exigencias y a sus necesidades. Porque distintas serán las demandas y distintos serán los problemas a los que hacer frente. La responsabilidad del Parlamento como expresión plural del poder público es grande en este tema.

Desde una reflexión crítica, dos son las cuestiones que pueden considerarse como más expresivas del deterioro del funcionamiento del Parlamento y de

1 En este sentido, M. WEBER, El Estado nacional y la política económica en Escritos políticos,Alianza, 1991, p. 44. El principio de eficacia es un elemento de tensión permanente inherente al Estado social con particular incidencia sobre los elementos configuradores del Estado de derecho. Sobre la relación y tensión Estado social/Estado de derecho, E. FORTSHOFF, Problemas constitucionales del Estado social en W. ABENDROTH, E. FORSTHOFF y K. DOEHRING, El Estado social, CEC, 1986, pp. 45-67. 
su posición en el entramado institucional. Por una parte, el progresivo desdibujamiento de las funciones parlamentarias. Por otra, la crisis de la representación en sí misma considerada. Ambas afectan directamente a la eficacia y legitimidad del control parlamentario.

Desde la primera, se ha llegado a afirmar que el Parlamento ha sufrido una verdadera expropiación de sus funciones ${ }^{2}$. Sin necesidad de aventurarse en afirmaciones radicales, es notorio que la función legislativa se encuentra hoy seriamente cuestionada, la deliberativa reducida a mínimos cuestionables y la de control, perpleja y vacilante ${ }^{3}$. Desde la segunda, se cuestiona la representatividad de unas cámaras prisioneras del sistema de partidos y de su correspondiente disciplina, sobre las que no es posible proyectar una relación entre la decisión y la responsabilidad política. En este cuestionamiento de la representatividad del Parlamento, influye también la escasa consideración que se tienen de los temas que se debaten. En el Parlamento, se dice, no se debaten las cuestiones que más interesan a los ciudadanos ${ }^{4}$.

En el análisis del Parlamento contemporáneo, es nota común subrayar como la traslación del sistema de partidos a la Institución ha provocado la sustitución de la tradicional dialéctica Gobierno/Parlamento por la que enfrenta a la mayoría parlamentaria con la minoría parlamentaria. Desde esta circunstancia, el control, vanguardia de la actividad parlamentaria, pierde gran parte de su significación y roza el convertirse en una función vacía. Este hecho, aceptado comúnmente y denunciado en múltiples ocasiones, que tiene innumerables consecuencias sobre la vida parlamentaria, no ha sido, sin embargo objeto de reflexión por parte de la propia Institución. De hecho, muchos de los cambios que se propugnan en relación con el Parlamento y que resultan necesarios para que éste recupere su credibilidad estarán vinculados a adoptar como punto de partida la dialéctica citada.

Una de las líneas de trabajo posibles sobre el Parlamento y sus funciones, arranca, pues, de observar el origen de su debilidad en no haber sabido dar for-

2 Así, S. LABRIOLA, La crisis del Parlamento desde la óptica italiana en Parlamento y democracia, Fundación Pablo Iglesias, 1981, ob. cit., p. 38. Por su parte, Enrique Guerrero llama la atención sobre como los gobiernos han ido adquiriendo funciones que tenía reservado el Parlamento (E. GUERrero SALOM, El Parlamento. Qué es, Cómo es, Qué hace, Síntesis, 2004, p. 25).

3 Respectivamente, D. LÓPEZ GARRIDO, Los debates parlamentarios en Parlamento y Derecho, Parlamento Vasco, 1991, p. 385 y X. VANDENDRIESSCHE, Le parlement entre déclin et modernité, Pouvoirs n. ${ }^{\circ}$ 99, 2001, p.59 (Sobre la posición del Parlamento en Francia durante la V República no ahorran adjetivos expresivos: déclin, décadence, affaiblissement, domestication, humillation).

$4 \mathrm{Al}$ respecto, el profesor Torcal analiza diversas encuestas del Centro de Investigaciones Sociológicas (M. TORCAL, La confianza en el Parlamento español. Tendencias, causas y consecuencias en Ciudadanía y política, Asociación Española de Letrados de Parlamentos-Fundación Manuel Giménez Abad, 2004, pp. 171-181). Véase también R. MONTERO y F. RODRIGO, Conocer el Parlamento: una selección de datos de encuesta sobre las Cortes Generales, RCG n. ${ }^{\circ} 20,1990$. En este punto, es bueno recordar a Ortega cuando advertía que, por encima de la corrección jurídica, los pueblos piden a sus instituciones una imponderable justificación y que si no se la dan, un día u otro, son tronchadas (J. ORTEGA y GASSET, Vieja y nueva política, Renacimiento, 1914, p. 39). 
ma al desplazamiento acaecido en el poder político. Esa carencia ha conllevado la su incapacidad para asumir con plenitud sus funciones de representación, legitimación y publicidad de la vida política. Funciones que, se insiste, debieran servir para hacer del Parlamento referencia inexcusable como elemento esencial del control del poder. Ello explica parte de sus disfunciones actuales y debiera ser, también, acicate para que sea en el interior de la propia Institución donde se inicie el proceso que ha de concluir en su renovación. Sin duda, sólo será posible si los principales agentes parlamentarios, grupos y diputados, así como partidos, entienden la singularidad y necesidad de la Institución. Si lo entienden hasta el punto de, al menos en la citada reflexión, ser más Institución que partido, se podrá decir que la batalla, al menos en sus aspectos más relevantes, ha sido ganada.

Desde las consideraciones anteriores, es necesario avanzar siquiera unas líneas sobre la actual relación entre parlamento y democracia. Sorprende que, de forma prácticamente general, el Parlamento esta ausente del debate sobre la democracia contemporánea. Nadie repara en esta Institución cuando se plantean sus problemas ni, por supuesto, cuando se exponen posibles soluciones. Puede decirse sin exageración que el Parlamento es una Institución invisible en la discusión contemporánea sobre la democracia. Lejos están aquellos años del periodo de entreguerras en los que la diatriba antidemocrática tuvo como eje la crítica a la Institución parlamentaria. Hoy no parece molestar pero tampoco parece importar. Ni a los protagonistas de la vida política ni a los ciudadanos ni a los teóricos ${ }^{5}$. Pienso que esta circunstancia se encuentra ligada a un cierto debilitamiento de la conciencia pública en relación con la transcendencia del control del poder político.

Sin embargo, el devenir de la Institución aparece como inseparable del presente de la democracia. La democracia es control del poder político y el Parlamento ha de ser el centro del ejercicio de dicho control. El Parlamento sufre del mismo desconcierto que sacude los cimientos tradicionales del funcionar democrático. Su debilidad no es sino un síntoma, y no de los menores, de la crisis de la democracia. Es posible compartir la idea de que hay que abandonar la convicción de que la política se inicia y se acaba en los parlamentos. Pero ello no debiera traducirse en el olvido del Parlamento. Afirmar que existe política fuera de los parlamentos y fortalecer los parlamentos son afirmaciones no sólo compatibles sino complementarias. Porque existe esa política es necesario un Parlamento fuerte que garantice la posición de liderazgo político desde la re-

5 Como bien indica Peces-Barba, la crisis del parlamentarismo no tiene hoy origen en enemigos externos sino en los demonios interiores (G. PECES-BARBA MARTÍNEZ, Reflexiones sobre el Parlamento en El Parlamento del Siglo XXI, Asamblea de Madrid, 2002, p. 67). En las últimas encuestas del Centro de Investigaciones Sociológicas (CIS) sobre la confianza en las instituciones, se pregunta sobre la televisión, los sindicatos, la banca, el gobierno, las fuerzas armadas o la Iglesia, pero no se pregunta sobre el Parlamento. Uno de los rasgos comunes a las democracias occidentales, es la posición de un Parlamento alejado de los ciudadanos del que éstos desconfían (M. SHAW, Overview: Parliamentary Democracy Today, Parliamentary Affairs Vol. 57 n. ${ }^{\circ}$ 3, 2004, p. 702). 
presentatividad y el ejercicio eficaz del control político. Porque existe política fuera de las cámaras, éstas deben iniciar con urgencia un proceso de comunicación con el exterior ${ }^{6}$. También el Parlamento necesita de la pausa y de la reflexión para, en su caso, emprender las reformas necesarias, aquellas que la conviertan en una Institución representativa de la sociedad compleja de principios del siglo XxI y adecuada en sus funciones a las nuevas demandas y posibilidades que ofrecen la sociedad y la técnica. La democracia, también en la era de las nuevas tecnologías y de los movimientos sociales, sigue pasando por el Parlamento.

La democracia, al menos tal y como se ha entendido hasta la fecha, no es posible sin una Institución que cumpla las funciones esenciales que le son asignadas al Parlamento ${ }^{7}$. En el sistema democrático representativo siempre deberá existir un órgano que legitime el poder político, que sirva a la integración y a la publicitación del actuar público, que garantice y represente el pluralismo político, y que desde todas esas funciones ejercite y escenifique el control del poder político. Puede recibir un nombre u otro, añadir o restar una función determinada, pero la esencia de lo que hoy representa el Parlamento es irrenunciable para la democracia. En el sistema parlamentario de gobierno, el Parlamento como órgano de la representación del pueblo sigue siendo un eslabón necesario en la cadena democrática de la legitimación ${ }^{8}$.

6 Institucionalizar la política fuera del parlamento y mejorar la representación en el Parlamento esta en la base de significativos esfuerzos teóricos como los realizados por autores como: W. KYMLICKA, J. COHEN y J. ROGERS, Secondary Associations and Democratic Governance, en E. O. WRIGHT, Associations and Democracy, 1995). No parece que esté cercano el momento en el que pueda darse por concluida la era institucional del poder (J. De ANDRÉS BLASCO, Las nuevas tecnologías en el ámbito parlamentario: realidades y perspectivas en Parlamento y nuevas tecnologias. II Jornadas parlamentarias de la Asamblea de Madrid, Asamblea de Madrid, 2003, p. 151).

7 Así, C. SCHMITT, Sobre el parlamentarismo, Tecnos, 1990, p. 40. No se trata de una opinión extravagante. De hecho, se encuentra relativamente difundida alrededor de análisis sobre la actualidad (entre otros, R. DAHRENDORF, Después de la democracia, Crítica, 2002, p. 86). La vinculación entre Parlamento y democracia esta en los mismos orígenes de la democracia contemporánea (H. KELSEN, Esencia y valor de la democracia, Labor, 1934, p. 48 -Kelsen considera que más allá de su relación con la democracia, no es posible desterrar al Parlamento de la organización del Estado moderno y aduce como prueba concluyente que hasta los regímenes autoritarios han necesitado invocar la autoridad de alguna asamblea-, ob. cit., pp. 56-58). "Sin Parlamento es posible tener Estado de derecho, Estado social pero democracia en modo alguno" (F. RUBIO LLORENTE, Las Cortes Generales. Introducción al Título III en Comentarios a la Constitución española de 1978 Tomo VI, Cortes Generales-Edersa, p. 24). En el mismo sentido, M. WEBER, Parlamento y Gobierno en un Alemania reorganizada, Alianza, 1991, p. 211. "No hay fórmulas alternativas a la parlamentaria si se quieren sistemas fundados en principios democráticos" (S. GINER, Carisma y razón, Alianza, 2003, ob. cit., p.138).

8 No es superfluo reivindicar la importancia de un buen funcionamiento de las instituciones para la consecución de los fines social y políticamente deseados. Sobre ello, R. DAHRENDORF, Ley y orden, Cívitas, 1994, pp. 157 y 158. Y en relación con esta afirmación, no esta de más recordar que las instituciones no son sólo norma (H. TRIEPEL, Derecho público y política, Cívitas, 1986, pp. 51-52); E. W. BÖCKENFÖRDE, Estudios sobre el Estado de derecho y la democracia, Trotta, 2000, p. 58. 


\section{LA DEFINICIÓN DEL CONTROL PARLAMENTARIO}

\section{PRIORIDAD ENTRE LAS FUNCIONES PARLAMENTARIAS}

Desde las consideraciones realizadas, es posible abordar una visión contemporánea de la función de control. Para la consecución de este objetivo, el Parlamento debe recuperar los frutos de la dialéctica poder/libertad, beneficiarse de su extraordinaria vigencia en el marco del debate sobre los posibles modelos sociales o políticos y, desde la misma, reivindicarse como escenario, como foro, tanto desde una perspectiva social como desde su consideración estrictamente institucional. Para ello, también, debe tomarse como premisa la consideración de que el destinatario del control es la sociedad, que el control se hace en sede parlamentaria pero no para convencer al oponente político sino para tratar de influir en la opinión pública.

En un análisis contemporáneo, el Parlamento tiene como primera función el control de la acción de Gobierno. Esta afirmación obliga, en primer lugar, a cuestionar la realidad de las funciones legislativa y presupuestaria. Son, éstas, funciones que hoy se encuentran, ya se ha dicho, alejadas del Parlamento en su sustantividad. Nadie desconoce que, en virtud de la sustitución del interés general por el criterio de la mayoría propio del Estado de partidos, es el Gobierno quien decide sobre las leyes y el presupuesto. Además, en el actual modelo social difícilmente puede ser de otra manera. La creciente complejidad financiera y de las materias objeto de legislación es argumento incontestable en favor del protagonismo del ejecutivo sobre las mismas. Ello no quiere decir que la actividad parlamentaria carezca de importancia. Sin duda, todavía el presente de su ejercicio ofrece notas de indudable interés para su análisis. Desde luego, uno de los retos fundamentales del nuevo modelo parlamentario será el de devolver a la ley cualidades hoy perdidas y hacerlo desde el reforzamiento de la relación ley/Parlamento. Pero la acción del Parlamento en relación con estas funciones será, siempre y básicamente, de control. Su decisión en relación con las mismas la adoptará no como sujeto primario sino como legitimador del Gobierno, como expresión de la mayoría que lo sostiene. Su producción en sede parlamentaria sirve, ante todo, al control del Gobierno. Ello es particularmente claro en relación con la función presupuestaria.

Una visión conjunta de las funciones parlamentarias y de su relación con la sociedad de la que emerge el Parlamento, otorga al control una posición superior en el conjunto de las funciones parlamentarias. Hasta el punto de que Parlamento y control político debieran aparecer como sinónimos ante una ciudadanía que necesita saber que el poder político esta sujeto a un control eficaz. Las instituciones no pueden perder esta función, no pueden dejarla en manos de terceros. Ello no significa, evidentemente, que el Parlamento aspire al monopolio de ese control. Ni es posible ni es realista ni es deseable. Tan sólo debe aspirar a ejercer un control eficaz y creíble. Para ello, dispone en la actualidad de medios superiores a los existentes en cualquier otra etapa histórica. 


\section{PResupuestos ClÁSICOS DEL CONTROL PARLAMENTARIO}

No es afirmación retórica señalar que la historia política de occidente se encuentra animada por dos fuertes impulsos: la fuerza del poder y la pasión de la libertad ${ }^{9}$. Poder y libertad están obligados a convivir formando un binomio que porta en sus venas los más eficaces anticuerpos. Precisamente, si algún éxito cabe atribuir al modelo político occidental es el de haber sabido equilibrar sus fuerzas y ofrecer cauces institucionales para la resolución de los inevitables conflictos. Gran parte de ese equilibrio descansa sobre la noción de control. Desde esta perspectiva, el control del poder político se ha erigido en clave de bóveda del edificio democrático.

La idea de control ofrece un significado especialmente atractivo si se toma en consideración su especial vinculación con el concepto de Constitución ${ }^{10}$. Pues bien, si el control es núcleo del sistema que el concepto occidental de Constitución presupone, hoy hay que proceder a examinar la presencia institucional de ese control. Y en una visión de conjunto, parece plausible aceptar la premisa de que en el moderno sistema político la dirección del Estado y la ejecución de las políticas es potestad del ejecutivo y que al Parlamento corres-

$9 \mathrm{Al}$ respecto, I. BERLIN, El fuste torcido de la humanidad. Capítulos de historia de las ideas, Península, 1992, p. 185. Sobre esta afirmación clásica y su relación con el control parlamentario, F. RUBIO LLORENTE, El control parlamentario en La forma del Poder, CEC, 1993, p. 243.

10 "Limitar el poder político quiere decir limitar a los detentadores del poder; esto es el núcleo de lo que en la historia antigua y moderna de la política aparece como el constitucionalismo" (K. LOEWENSTEIN, Teoría de la Constitución, Ariel, 1983, p. 29). “Por Constitución... entendemos y entiende hoy lo mejor de la doctrina, un modo de ordenación de la vida social en el que la titularidad de la soberanía corresponde a las generaciones vivas y en el que, por consiguiente, las relaciones entre gobernantes y gobernados están reguladas de tal modo que éstos disponen de unos ámbitos reales de libertad que les permiten el control efectivo de los titulares ocasionales del poder" (F. RUBIO LLORENTE, La Constitución como fuente del Derecho en La Constitución española y las fuentes del Derecho, Vol I, 1981, p. 69). Véase al respecto, M. ARAGÓN REYES, El control como elemento inseparable del concepto de Constitución, REDC n. ${ }^{\circ} 19,1987$. Síntesis de esta doctrina puede verse en, I. FERNÁNDEZ SARASOLA, El control parlamentario y su regulación en el ordenamiento español, REDC n. ${ }^{\circ}$ 60, 2000, pp. 91-92.

11 En realidad, si se atiende a los antecedentes históricos del Parlamento contemporáneo, la función de control se encuentra en el origen mismo del Parlamento, siendo previa a la legislativa hasta la Revolución Francesa (E. GUERRERO SALOM, El Parlamento. Qué es, Cómo es, Qué hace, ob. cit., p. 210). Por su parte, M. Weber identificaba al Parlamento que trabaja con el Parlamento que interviene de manera permanente en el control de la administración, M. WEBER, Parlamento y gobierno en una Alemania reorganizada, ob. cit., pp. 170-178. Para Stuart Mill, la verdadera misión de una Asamblea representativa no es gobernar, tarea para la que resulta radicalmente impropia, sino vigilar e intervenir al Gobierno (J. STUART MILL, Del gobierno representativo, Tecnos, 1985 p. 65). Para Montero Gibert y García Morillo, "Todo esto permite calificar al control parlamentario como el núcleo esencial de las relaciones entre el legislativo y el ejecutivo y al mismo tiempo, como una de las piezas básicas del edificio teórico y constitucional del parlamentarismo" (J. GARCÍA MORILLO y J. R. MONTERO GIBERT, El control Parlamentario, Tecnos, 1984, p. 18). Sobre la función de control, A. MANZELLA, Il Parlamento, Il Mulino, 1977, pp. 355-366; F. SANTAOLALLA LÓPEZ, Derecho parlamentario español, Editora Nacional, 1984, pp. 198-203; VV. AA., Parlamento y control del gobierno, Asociación Española de Letrados de Parlamentos-Aranzadi, 1998; J. GARCÍA MORILLO y J. R. MONTERO GIBERT, El control parlamentario, ob. cit. 
ponde protagonizar y fortalecer el control de las funciones ejercidas por el ejecutivo.

De acuerdo con las consideraciones precedentes, no puede extrañar que el Parlamento se convirtiese históricamente en protagonista del control del poder político. La función de control ha sido desde sus inicios una de sus funciones definitorias en paridad con la función legislativa ${ }^{11}$. Ahora bien, desde el propio Parlamento se ha consolidado un concepto excesivamente juridicista. El mismo se encuentra vinculado a la existencia de instrumentos jurídicos de sanción y corrección y ha sido construido desde una estricta visión formalista de la Institución ${ }^{12}$.

Pero no se trata sólo de un concepto construido desde una determinada visión de la relación entre el Derecho y el Parlamento. Se trata, además, de un concepto elaborado desde un modelo parlamentario, en el que la forma de actuar la responsabilidad del Gobierno ante el Parlamento era claramente diversa a la que rige en el Estado de partidos. Así, el presupuesto de ese modelo y del concepto de control vigente en nuestros días, es un Parlamento que es órgano para deliberar y, en su momento, adoptar decisiones. Un Parlamento que vive en contraposición y dialéctica permanente con el poder ejecutivo. Hace tiempo, es sabido, que ese modelo, si es que alguna vez existió, ha desaparecido. Hoy el Parlamento es escenario donde se representan los conflictos y las decisiones pero no forjador de las mismas. Hoy el Parlamento no vive en contraposición al Gobierno. Hoy, la dialéctica que lo caracteriza, se ha visto, es la que enfrenta a la mayoría con la minoría ${ }^{13}$. En virtud del juego de los partidos políticos y de sus representantes en las cámaras, los grupos parlamentarios, el Parlamento ha pasado a ser el lugar donde el Gobierno se controla a sí mismo a través de la posición que le otorga su mayoría parlamentaria. El ejercicio de la función, y la función propiamente dicha, cambia radicalmente de sentido. Así, se ha llegado

12 La tesis que reduce la función de control a un concepto estrictamente jurídico tiene un claro exponente en el profesor Santaolalla (F. SANTAOLALLA LÓPEZ, La función de control y la ciencia del derecho constitucional, RCG n. ${ }^{\circ} 12$, 1987). Su presupuesto es examinar esta función sólo desde el derecho, eliminando la perspectiva sociológica y política, desde las cuales, reconoce el autor, se puede dar una visión más amplia de control. Lo que sucede es que el estudio del Parlamento no admite tal reduccionismo. Una visión global del mismo y de cualquiera de sus funciones exige también tener presente las citadas perspectivas sociológica y política. Es más, habría que decir que, estudiando el Parlamento, el enfoque debe ser eminentemente político. Ello no obvia, en ningún caso, la pertinencia y necesidad de los análisis jurídicos. Sobre la reducción formalista de la función de control, M. SÁNCHEZ de DIOS, La práctica del control parlamentario en el Congreso de los Diputados entre 1977 y 2000, RCG n. ${ }^{\circ}$ 57, 2002, p. 100. Sobre la naturaleza eminéntemente política del Parlamento a la hora de examinar la función de control, J. GARCíA MORILLO y J. R. MONTERO GIBERT, El control Parlamentario ob. cit., p. 28.

$13 \mathrm{Al}$ respecto, M. SÁNCHEZ de DIOS, La práctica del control parlamentario en el Congreso de los Diputados entre 1977 y 2000, ob. cit., p. 101. En relación con la división mayoría/minoría y su repercusión sobre la función de control, Requejo subraya como el control pasa por esa divisoria y como en esas circunstancias la institucionalización de las minorías y la consiguiente formalización de los componentes de la realidad que conforma el Estado de partidos se convierte en una necesidad (J. L. REQUEJO PAGÉS, Las relaciones entre el Gobierno y las Cortes Generales, REDC n. ${ }^{\circ}$ 70, 2003, p. 87). 
a decir que, en las actuales circunstancias, seguir hablando de control del Parlamento sobre el Gobierno supone la utilización de categorías anacrónicas ${ }^{14}$.

Un examen pormenorizado de la función de control y de su evolución en relación con el Parlamento demuestra como ha soportado y soporta muy fuertes dosis de ambigüedad ${ }^{15}$. También ha sido, prácticamente siempre, una noción limitada. Nunca ha existido un control absoluto. Ninguna de estas dos características ha ayudado a la función que se examina. El tiempo sólo ha acentuado los rasgos comentados, pudiendo decirse que en la actualidad el primer problema de la función de control es su propia definición. Al respecto, también hay que recordar como el impulso doctrinal a la denominada función de orientación política, no ha hecho sino acrecentar las dudas y las sombras en relación con el control ${ }^{16}$. La barrera que separa una y otra función no es nítida y esta situación ha favorecido la consolidación de la ficción de un Parlamento en el que el Gobierno controla a la mayoría y que, a su vez, debe controlar al Gobierno controlado. En realidad, si se abandona un enfoque meramente jurídico, la distinción podría ser clara si se acepta que, salvo en circunstancias extraordinarias, la acción parlamentaria de la minoría en relación con el Gobierno es control y la que ejerce la mayoría es orientación política. El control se definiría por la intención última de la acción emprendida y aunque no es descartable que desde la oposición se pueda llegar a hacer actividad de mera orientación, desde el momento en que se realiza por esa minoría la acción ha de ponerse en relación con su objetivo último de desgastar al Gobierno para buscar el relevo.

También es clásica la disyuntiva entre control y responsabilidad. Bajo una misma finalidad, los instrumentos parlamentarios que entrarían en la definición

14 Esta es la expresión utilizada por el profesor Rubio Llorente, F. RUBIO LLORENTE. El futuro de la Institución parlamentaria en El Parlamento y sus transformaciones contemporáneas, Tecnos, 1991, p. 387 (asimismo, F. RUBIO LLORENTE, El control parlamentario, ob. cit., pp. 253-254). En una análisis del control parlamentario ejercido en las Cortes Generales en los primeros veinticinco años de Constitución, el profesor Requejo observa que si algo han demostrado esos años es que el control del poder, algo definitorio del Estado constitucional, no puede confiarse a un órgano dominado por el poder político que también conforma al órgano controlado (J. L. REQUEJO PAGÉS, Las relaciones entre el Gobierno y las Cortes Generales, ob. cit., p. 87). García Morillo y Montero Gibert describen la crisis de la función de control en el marco de la crisis general del Parlamento, J. GARCÍA MORILLO y J. R. MONTERO GIBERT, El control Parlamentario, ob. cit., pp. 45-50.

15 Así, el profesor, Sánchez de Dios estima que "Cuando queremos determinar el contenido de lo que es el control parlamentario nos enfrentamos a un problema de ambigüedad", y subraya que el control parlamentario supone básicamente obtener información; hacer propuestas para orientar al Gobierno; y sancionar la acción de gobierno bien mediante crítica bien mediante la responsabilidad (M. SÁNCHEZ de DIOS, La práctica del control parlamentario en el Congreso de los Diputados entre 1977 y 2000, ob. cit., pp. 102-103). Esta enumeración, que puede considerarse representativa, al menos de un concepto amplio de control, es elocuente de la diversidad de las cuestiones que se engloban bajo el epígrafe control. Por su parte, Aguiar de Luque, señala que pocas nociones hay tan esquivas como la de control parlamentario (L. AGUIAR de LUQUE, La problemática del control en la actualidad en El Parlamento a debate, Trotta-Fundación Lucas Mallada, 1997, p. 73).

16 Sobre la función de orientación política, A. MANZELLA, Il Parlamento, ob. cit., pp. 261-290. 
de responsabilidad serían aquellos que estarían vinculados a la existencia de consecuencias jurídicas, como la remoción del controlado. Así, la moción de censura y la cuestión de confianza suelen ser los instrumentos ligados a la idea de responsabilidad. En estas páginas se mantendrá esta distinción, si bien no se dejará de insistir en la idea de que, y más en un modelo de parlamentarismo fuertemente racionalizado, los instrumentos anteriormente citados son, en la práctica, más una variante del control que la representación de la responsabilidad en sentido estricto.

\section{AlgunA REFLEXIÓN NECESARIA PARA UNA VISIÓN CONTEMPORÁNEA DEL CONTROL}

Definir, o al menos, intentar comprender la función de control en el Parlamento actual, exige tener en consideración una serie de cuestiones que no suelen ser percibidas, al menos en demasiadas ocasiones, por los propios agentes protagonistas. El control se ejerce sobre una realidad que se transforma de manera acelerada. El control se ejerce sobre unos presupuestos políticos y jurídicos que no son los que configuraron los presupuestos clásicos del mismo. Sus fronteras, como habrá de verse, no son las que eran. El control, en fin, se ejerce con unos instrumentos que cada día muestran nuevas posibilidades. Todo ello debe ser tomado en consideración no sólo con un afán de comprensión, sino, lo que es más relevante, si se desea introducir los cambios precisos para que la función no quede en mera retórica.

En general, los problemas para poder ejercer de manera eficaz esta función se multiplican y, así, aunque los medios a disposición de las instituciones parlamentarias se han incrementado considerablemente, la efectividad del control no ha crecido. De esta manera, pueden citarse como dificultades más destacadas, y simplemente a modo de ejemplo, la huida del Derecho administrativo con la consiguiente creación de empresas públicas y otros entes ajenos al control parlamentario; la privatización de los antiguos servicios públicos; la nueva relación poder/territorio; la evolución de los medios de comunicación social; las limitaciones en cuanto a la obtención de una información propia; las carencias en relación con el control presupuestario, perfectamente ejemplificadas en la triste vida que han tenido las diferentes propuestas de creación de oficinas de control presupuestario o, por dejar para el final la más significativa, la contundencia de la primacía de la mayoría sobre la minoría ${ }^{17}$.

$17 \mathrm{Al}$ respecto, véase, E. GUERRERO SALOM, El Parlamento. ¿Qué es, Cómo es, Qué hace?, ob. cit., pp. 240-242; M. CASTELLS, La galaxia Internet, Plaza-Janés, 2001, p. 138; F. PAU i VALL, Una reflexión sobre el estado del Parlamento y su potenciación en Parlamento y opinión pública en Parlamento y opinión pública, Asociación Española de Letrados de Parlamentos-Tecnos, 1995, pp. 30-31. Lo señalado no obsta para que, si se atiende a las estadísticas del trabajo parlamentario, pueda observarse como la tarea de vigilancia y control ha crecido notablemente, intensificándose con el paso del tiempo (M. SÁNCHEZ DE DIOS, La práctica del control parlamentario en el Congreso de los Diputados entre 1977 y 2000, ob. cit., p. 127). 
Una reflexión especial exige la relación existente entre la función examinada y los medios de comunicación. Es opinión común que éstos desempeñan un papel de singular relevancia en la política en general y con referencia al Parlamento en particular. Pocos dudan que es éste uno de los datos esenciales para comprender el sistema político vigente. Se trata de un extraordinario poder no formalizado que ha alterado sustancialmente el funcionamiento de los restantes poderes sobre todo en lo relativo a sujetos y objeto del control. Lejos de considerar y replicar a su irrupción, el Parlamento ha vivido ajeno a esta circunstancia y ni siquiera se ha preocupado, al menos hasta fechas recientes, por su presencia en los mismos. Adecuar el Parlamento al presente pasa por determinar cuál ha de ser la relación del Parlamento con esos medios, y, en general, por fijar una moderna política de comunicación. Si ello tiene importancia en relación con la consideración global del trabajo parlamentario, su importancia resulta decisiva en relación con la función de control. De nada sirve cualquier ejercicio de control realizado por el Parlamento o uno de sus miembros, si esa actuación no transciende a la sociedad. Y la única manera de lograrlo es consiguiendo que la misma posea lo que se viene denominando efecto mediático. No es por tanto osado señalar que el control parlamentario tiene en realidad dos momentos procedimentales. El estrictamente parlamentario y el de su presencia en los medios. Por ello, no es suficiente con alegar la naturaleza extraparlamentaria de la segunda fase para finalizar el debate. El Parlamento no sólo deberá hacer esfuerzos para lograr el citado impacto sino que también tendrá que desarrollar una política informativa propia que permita asegurar la recepción social de todas sus actividades y, singularmente, de aquellas que implican control del Gobierno $^{18}$.

Sin ánimo de adelantar conclusiones, puede afirmarse que se esta materializando un fenómeno de "huida del control parlamentario", fenómeno al que no es ajeno el radical fortalecimiento de lo privado en consonancia con el debilitamiento de lo público. Definir, redefinir, el ámbito del control a ejercer por el Parlamento y hacerlo desde la premisa de que todo lo que afecta al interés general debe ser susceptible de control o, por lo menos, de conocimiento por parte de la Institución parlamentaria, se antoja como esencial en la tarea de adaptar al nuevo modelo social no sólo el Parlamento sino el sistema político en su conjunto.

El control de las decisiones políticas es un elemento irrenunciable del Estado democrático y su importancia crece a medida que se amplía la esfera de actuación del poder público y las exigencias ciudadanas al respecto. El actual modelo parlamentario no responde a esta necesidad. Los presupuestos que han servido a la construcción de la teoría y de los instrumentos actuales del control han cambiado notablemente y lo siguen haciendo. Por todo ello, se hace im-

18 Sobre la vinculación entre información parlamentaria y control, L. AGUIAR de LUQUE, La problemática del control en la actualidad, ob. cit., p. 79; J. TUDELA ARANDA, La función parlamentaria de información política en Parlamento y medios de comunicación, Asociación Española de Letrados de Parlamentos- Tecnos, 20005, pp. 53-74. 
prescindible ejercer de manera diferente el control. En realidad, es preciso ir más allá. Se trata de dar una nueva dimensión a una función que emerge como referencia necesaria del Parlamento contemporáneo. Para ello, no debe olvidarse cuál es el primer valor que en relación con el control ofrece el Parlamento en el presente. Como señaló el profesor Rubio Llorente, el Parlamento es locus del control. Y debe reivindicarse la importancia de poseer el escenario, de tener a disposición el espacio natural del control político. El espacio no sólo transmite sino que también legitima. Desaprovechar esta circunstancia sería un grave error. La adquisición del rol de agente en la función de control debe hacerse desde la obtención del máximo rendimiento a la ventaja adquirida que supone la situación antedicha.

En la actualidad, puede afirmarse, el control parlamentario de la acción del Gobierno es más intenso y más débil que nunca. El incremento de la intensidad de su ejercicio no se ve correspondido ni por una mayor eficacia ni por una mayor credibilidad del trabajo parlamentario. Aumentar la eficacia en el ejercicio de la función de control y aprovechar la mayor disponibilidad de medios a su disposición es un reto ineludible para el nuevo Parlamento. Un mejor ejercicio de esta función y su percepción por la ciudadanía serían por sí solos elementos revitalizadores de la Institución.

El desarrollo de esa noción de control persigue consolidar la idea de un Parlamento temible para el ejecutivo. De acuerdo con la afortunada afirmación de Sartori, la importancia del Parlamento no radicaría sólo en lo que hiciera sino en lo que impediría hacer ${ }^{19}$. El Parlamento podrá y deberá realizar otras tareas. Pero entre ellas deberá seguir emergiendo como nota característica la de proyectarse sobre la ciudadanía como aquella institución que sirve a una limitación y control efectivo del poder. Entre otras cosas, porque no existe en el mapa político una institución que pueda realizar esta tarea. Su desarrollo ha de contribuir a adaptar la sensibilidad mayoritaria a los cambios sociales, así como para armar a la minoría de cara a los futuros procesos electorales. Esta caracterización debiera servir también para diferenciar con nitidez los ámbitos de actuación del poder legislativo y del poder judicial, reduciendo la esfera de este último a aquello que es estrictamente objeto de su competencia, el ejercicio del correspondiente control de legalidad.

La consideración del Parlamento como foro protagonista del control del poder político debiera ser una de las líneas primeras a emprender en la tarea de su renovación. Es, se piensa, la primera función que la sociedad le atribuye y la primera que desearía se ejerciese adecuadamente. Puede decirse que un nuevo Parlamento pasa, ineludiblemente, por una nueva concepción del control, por un control más visible y eficaz.

19 Así, P. BISCARETTI DI RUFFÍA, Derecho constitucional, Tecnos, Madrid, 1984, pp. 403 y ss.; M. ARAGÓN REYES, El control como elemento inseparable del concepto de Constitución, ob. cit; G. SARTORI, Elementos de teoría política, Alianza, 1992, p. 201. 


\section{EL PARLAMENTO COMO RECEPTOR DE INFORMACIÓN}

Como se ha indicado, el control del poder público no es sólo la más importante de las funciones que en la actualidad tiene encomendadas el Parlamento sino que puede decirse que todas las funciones que tradicionalmente le han sido atribuidas son reconducibles a una noción última de control $^{20}$. Es desde esta premisa desde la que hay que entender la importancia que se debe otorgar a su consideración como receptor de información. Se entiende que sólo un Parlamento con medios de información suficientes y autónomos puede enfrentarse al desequilibrio que caracteriza sus relaciones con el poder ejecutivo. La existencia de esa información es presupuesto de un correcto ejercicio del control. Sin información suficiente y adecuada no hay control posible ${ }^{21}$.

Junto a ello, es obligado detenerse en la influencia que las transformaciones del modelo social y tecnológico poseen sobre esta cuestión. Si el modelo que emerge como consecuencia del desarrollo tecnológico y, en concreto, de Internet es el derivado de un paradigma de la tecnología de la información; si una de las principales características del mismo es que gravita sobre tecnologías que actúan sobre la información; si esas tecnologías derivan a un modelo global de información; si de la mano de la información esas tecnologías van a penetrar en todos los procesos de la acción humana, puede entenderse que uno de los paradigmas esenciales del funcionamiento del Estado democrático va a sufrir una transformación radical. El Parlamento no sólo no es ajeno a este proceso sino que, puede afirmarse, es Institución singularmente afectada por el mismo.

En relación con la recepción de información, y desde el presupuesto de su significación para el ejercicio de la función de control, una cuestión esencial es la de la autonomía del Parlamento para disponer de esa información ${ }^{22}$. Asegu-

$20 \mathrm{Al}$ respecto, pueden citarse: F. RUBIO LLORENTE, El control parlamentario en La forma del poder, ob. cit., p. 256; I. FERNÁNDEZ SARASOLA, El control parlamentario y su regulación en el ordenamiento español, ob. cit., p. 90; A. MANZELLA, El Parlamento en el siglo XXI en El Parlamento del Siglo XXI, Asociación Española de Letrados de Parlamentos-Tecnos, 2002, p. 42. Por su parte, el profesor ARAGÓN señala que el control parlamentario no encaja en un concepto jurídico pero sí en uno político y llega a la conclusión de que ese control se expresa en todas las manifestaciones parlamentarias. Para Vandendriessche, entre su papel de órgano de decisión y su papel de órgano de control, prevalece su condición de órgano de control (X. VANDENDRIESSCHE, Le parlement entre déclin et modernité, Pouvoirs n. ${ }^{\circ}$ 99, 2001, p.63).

21 En este sentido, A. CHANDENAGOR, Un Parlement, pour quoi faire?, Gallimard, París, 1967. El profesor López Guerra llega a señalar que el control es una función de información, de disfusión de la información (L. LÓPEZ GUERRA, La función de control de los Parlamentos: problemas actuales en El parlamento y sus transformaciones actuales, ob. cit., p. 245). La información como derecho del parlamentario, A. EMBID IRUJO, El derecho a la información del Parlamento y de los parlamentarios. Nuevas reflexiones a la luz de las innovaciones del ordenamiento jurídico, Anuario Jurídico de La Rioja n. ${ }^{\circ}$ 2, 1996. Sobre las diferencias entre la función de información y la de control y la instrumentalidad de la primera en relación con la segunda, J. GARCÍA MORILLO y J. R. MONTERO GIBERT, El control Parlamentario, ob. cit., pp. 65-68.

22 En palabras del profesor Manzella: «La autonomía informativa es, en los modernos sistemas constitucionales, el dato más significativo para valorar el peso específico de los poderes parlamentarios" (A. MANZELLA, Las Cortes y la Constitución, en el vol. col. La Constitución española de 
rarla a la hora de recabarla se antoja cuestión fundamental. Para ello, no sólo ha de tener acceso a aquella que se encuentre en poder del ejecutivo sino que ha de generar y acceder a canales propios o ajenos que le aseguren la independencia. Uno de los datos fundamentales para comprender la realidad del Parlamento contemporáneo es el de su desequilibrio frente al poder ejecutivo. Inferioridad de medios materiales y personales que resulta particularmente sensible en cuestiones esenciales al funcionamiento parlamentario como es todo lo referido a la información, llegando a afectar a su capacidad para cumplir sus funciones primarias. La reflexión acerca de la relación entre Parlamento e información debe iniciarse alrededor de este dato.

Para alcanzar el objetivo de la autonomía, el Parlamento deberá cambiar los medios de los que dispone actualmente. La informática tradicional ya ha introducido significativos elementos correctores, paliando en parte esa situación de desequilibrio. Hace tiempo que esos medios han proporcionado a los agentes parlamentarios la posibilidad de obtener mayor cantidad de información y, sobre todo, de tratarla más adecuadamente. Así, pueden citarse a modo de ejemplo, el desarrollo de las bases de datos que ha permitido un archivo y acceso a la información mucho más rápido y eficaz o la propia generalización del uso de Internet en el interior de las cámaras como herramienta de documentación. U otros avances que, como la digitalización de resúmenes de prensa y dossieres de trabajo, pueden considerarse menores pero que en la práctica facilitan sobremanera el trabajo diario de los diputados. Se trata, sin duda, de pasos relevantes que han fortalecido a las instituciones parlamentarias. Ahora bien, debería irse más allá23.

El dato fundamental es que una utilización inteligente y racional de las nuevas tecnologías permite a la Institución parlamentaria acceder a cualquier información y, desde luego, a toda la información existente en manos del poder ejecutivo. Ya no es posible aludir a fronteras físicas para limitar el acceso a la información de los parlamentarios. Desde luego, para desplegar toda la fuerza de este aserto se necesita la colaboración del poder ejecutivo. Y también la concienciación de diputados y grupos parlamentarios. Éstos han de entender que su tradicional inferioridad en relación con el poder ejecutivo no es algo natural e imposible de resolver. Diputados y grupos parlamentarios debieran ser quienes impulsasen decisivamente la ruptura de las barreras a las que tradicionalmente se ha enfrentado la información parlamentaria y que hoy son plena-

1978. Estudio sistemático, dirigido por los profesores A. PREDIERI y E. GARCÍA DE ENTERRÍA, Cívitas, 1981, pp. 492-493).

23 En este sentido, M. HELGE HJORDTAL, Rapport sur les technologies de l'information au sein des parlements, Informations Constitutionnelles et parlementaires n. ${ }^{\circ} 161$, 1991, p. 6.; A. CAMPBELL, A. HARROP y B. THOMPSON, Towards the Virtual Parliament-What computers can do for MPs, Parliamentary Affairs, Vol 52 n. ${ }^{\circ} 3$, 1999, p. 385. Por su parte, Manuel Delgado-Iribarren considera que en la búsqueda de esa autonomía, las nuevas tecnologías resultan una ayuda imprescindible (M. DELGADO-IRIBARREN GARCÍA-CAMPERO, Las nuevas tecnologías en la vida parlamentaria, RCG n. ${ }^{\circ}$ 52, 2001, pp. 311-312). 
mente superables. Hay que repetirlo. Cualquier información puede ser accesible para los sujetos parlamentarios.

Entre los nuevos medios que la tecnología ofrece a las cámaras para la recepción de información merece mención singular Internet. Para éstas posee un valor añadido ya que puede utilizarse para obtener información directamente aportada por los ciudadanos. La Red permite a diputados y grupos multiplicar infinitesimalmente su capacidad para recibir información directamente desde la ciudadanía. Se trata de una información que puede enriquecer directamente el conocimiento o de una información que puede transmitir sensaciones, percepción de un determinado estado de ánimo de la opinión pública. Se trata de un canal de comunicación continua con los ciudadanos que debe ser utilizado activamente por la Institución y por sus diferentes agentes. Para ello, no sólo deberán disponerse los correspondientes instrumentos técnicos, por lo general ya implantados en casi todos los parlamentos, sino que también habrá que articular los medios necesarios para que se adquiera conciencia pública de la existencia de este circuito hasta que los ciudadanos lleguen a articularlo en su rutina cívica. El mero hecho de generalizar este intercambio de información, transformaría los paradigmas clásicos del control en sede parlamentaria.

Tratar de la información en sede parlamentaria debe ser también considerar los límites de la misma. Es ésta una cuestión sensible con múltiples aristas y bajo la cual se hace referencia a cuestiones diversas como el grado de publicidad que debe tener la información, que, así, puede ser diferente según sea la obtenida por el propio Parlamento del exterior o se trate de información generada directamente por el mismo; su relación con determinados derechos fundamentales o la distinción entre información/grupos parlamentarios e información/Institución. Todo ello requiere de un análisis pormenorizado que atienda y pondere los diferentes intereses y exigencias jurídicas en juego. En estas líneas, sólo puede subrayarse la complejidad del debate y la necesidad de hacer frente al mismo, salvaguardando, en cualquier caso, la garantía de una información adaptada a las necesidades del mundo contemporáneo.

No es exagerado decir que el correcto ejercicio del control y, en general, de la práctica totalidad de las funciones parlamentarias, pasa por poseer una información adecuada. No sólo la cantidad sino la calidad de la información que se posea va a ser decisiva para el ejercicio de esas funciones. La importancia de la información no ha hecho sino crecer. La mayor complejidad del Estado ha incrementado en paralelo las necesidades de información. De una información que, cada día, se requiere más selecta, más elaborada. Una información que, para ser útil, deberá estar directamente vinculada al proceso de toma de decisiones $^{24}$.

24 En este sentido, M. MACIÁ, Sistemas de información parlamentaria y nuevas tecnologías, RCG, n. ${ }^{\circ} 30,1993$, p. 231; M. R. RIPOLLÉS SERRANO, La irrupción de las nuevas tecnologías en los archivos y registros parlamentarios en Parlamento y nuevas tecnologias. II Jornadas parlamentarias de la Asamblea de Madrid, Asamblea de Madrid, 2002, p. 119; I. ASTARLOA HUARTEMENDICOA, Elementos para el desarrollo de la cooperación parlamentaria, Corts n. ${ }^{\circ}$ 6, 1998, p. 140. 


\section{SOBRE ALGUNOS INSTRUMENTOS NO TRADICIONALES DE EJERCICIO DE LA FUNCIÓN DE CONTROL Y SU GARANTÍA}

$\mathrm{Al}$ aludir a instrumentos no tradicionales, se hace referencia a instrumentos que, como la pregunta, la interpelación, la comparecencia o la proposición no de ley, suelen ser ligados a esta función, no sin dudas sobre su posible consideración como instrumentos de mera información, así las preguntas o de orientación política, así las proposiciones no de ley. La relevancia de estos instrumentos para una visión diferente del control, sin ser nula, es menor. Es cierto que la introducción en el régimen jurídico de los mismos de algunas modificaciones podrían vigorizarlos como instrumentos de control. En particular, las interpelaciones podrían ser proclives a esa vigorización. En cualquier caso, su análisis pasaría por unas reflexiones que no son el objetivo de estas páginas. A continuación, se hace alusión a fórmulas e instrumentos del control inexistentes o casi totalmente diluidos. La única excepción es la referencia a la comisión de investigación, por sus propias y específicas características.

El objeto de estas líneas será destacar algunos aspectos del quehacer institucional bien por su singularidad bien por las novedosas perspectivas que en relación con el control se abre para los mismos. Comenzando por el principio, tanto atendiendo a criterios cronológicos como de significación política, hay que llamar la atención sobre el valor que como elemento de control de la acción de gobierno puede tener el programa con el que el/los partidos que lo sustentan consiguieron la mayoría ante el electorado. Es cierto que en la actualidad el citado documento-programa esta muy devaluado y que casi es una premisa compartida que poco de su contenido va a ser efectivamente cumplido. Pero que esto sea así, no implica que necesariamente tenga que ser así ni, por supuesto, que ello sea positivo. Es más, puede decirse que el Parlamento hace una dejación importante de sus funciones en tanto que no somete a control periódico no ya el cumplimiento del programa con el que se acudió a las elecciones sino aquél con el que se obtuvo la mayoría necesaria para gobernar.

No parece que sea extraordinariamente complejo dar la vuelta a esta situación. Simplemente, una mayor escenificación y publificación del programa facilitaría esta tarea. Es preciso tanto el poner en valor el documento que sirve para obtener mayoría tan valiosa como la acción de control sobre el mismo. Al margen de los numerosos instrumentos de los que se dispone en sede parlamentaria para realizar esta tarea, y que deberían ser revisados al objeto de ser regulados en clave especifica del citado documento, cabe pensar en la incorporación de otros nuevos como podría ser la introducción de una rendición de cuentas singularizada en los anuales debates sobre el estado de la Nación/Comunidad Autónoma o la celebración mediada la legislatura de un debate específico al respecto.

En relación con este punto, no debe desecharse la importancia que puede tener el control directo por parte de los ciudadanos. Ello sería posible si dicho programa fuese expuesto en la página web del Parlamento, siendo así sus- 
ceptible de ser constantemente examinado. Al objeto de facilitar esta posibilidad de control ciudadano, imponer una cierta definición de sus contenidos podría ayudar poderosamente al respecto. Así, sin llegar a determinismos incompatibles con la tarea política, sí es posible pensar en hacer obligatoria la introducción de un catálogo de propuestas concretas con el correspondiente cronograma. Las referencias pueden ser más o menos rígidas pero nunca sería inconveniente que los ciudadanos perciban la existencia de compromisos claros y evaluables. En todo caso, parece obligado, por meras exigencias de transparencia informativa, por el derecho a la información que debe caracterizar la nueva sociedad, que, al menos, se adquiera la costumbre de publicitar el citado programa. Simultáneamente, se reforzaría la legitimidad política del gobernante.

La referencia al programa subraya la necesidad de que el Parlamento de ingreso al denominado control evaluativo con referencias y plazos concretos $^{25}$. Con la introducción de este control no sólo se ganaría en eficacia. También se incrementaría de manera notable la objetividad del mismo y, con ello, su credibilidad. Este extremo se antoja de especial importancia. Es necesario que los ciudadanos puedan adoptar opinión sobre las acciones de control desde criterios que superen su particular posicionamiento político. Para ello, hay que transmitir un control político verificable en los juicios, al menos cuando se refiera a acciones u omisiones del poder ejecutivo. Lógicamente, este control tiene una correspondencia obligada en la exigencia de procurar del Gobierno un grado mayor de concreción. No se trata de encerrar la política y la acción de gobierno en una rigidez que, amén de perjudicial, sería imposible. Se trata, tan sólo, de buscar el compromiso concreto allí donde tiene terreno abonado. Y que, al menos, en caso de incumplimiento, exista la necesidad de la explicación.

Un instrumento del trabajo parlamentario que puede venir en ayuda del control es la función de estudio. Bajo este nombre se agrupan los trabajos parlamentarios dedicados a una materia concreta, fruto, normalmente, de una comisión creada específicamente al respecto. Este tipo de trabajo sirve al Parlamento para fijar posición sobre una cuestión determinada, normalmente al margen de un debate político concreto y alcanzando, en general, un alto grado de acuerdo sobre sus conclusiones. Estrictamente, se trata de una función específica más ligada a la presencia social del Parlamento y a la función de orientación que a la de control. Pero no puede desdeñarse su utilidad para la función analizada. El mero hecho de analizar y estudiar un tema en sede parlamentaria, oyendo a los sectores sociales afectados y a especialistas, implica un cierto control de la acción de gobierno, porque, necesariamente, las miradas de parlamentarios y comparecientes en uno u otro momento se tendrán que dirigir al poder ejecutivo. Además, aunque sólo fuese de forma pasiva, por lo que de llamada de atención supone sobre un tema concreto, el ejercicio de esta función

$25 \mathrm{Al}$ respecto, véase, J. ASENSI SABATER, La retirada del discurso de la representación política en el debate sobre la crisis de la representación política, 1996, p. 101. 
adquiere una dimensión de control. Desde luego, como sucede prácticamente con todos los instrumentos de control, su efectividad estará estrechamente vinculada a la capacidad que se posea de trasladar a la sociedad el trabajo realizado.

Entre los nuevos instrumentos que merecen atención, una posición singular ocupa el derecho de petición, a caballo entre el control y la participación. Este derecho, convenientemente revitalizado y puesto al día, debe convertirse en una poderosa herramienta para el ejercicio de la función analizada. Se trata, desde luego, de una manifestación externa del control, pero es también control interno desde el momento en el que su ejercicio puede abrir caminos a la actuación estrictamente parlamentaria bien por haber aportado información novedosa bien por haber denunciado una situación desconocida. Sin duda, la fuerza del derecho de petición como instrumento de control estará directamente relacionada con la regulación que del mismo se haga. Por ello, las cámaras debieran, en la regulación interna que han de acometer del citado derecho, primar esta perspectiva e idear cauces para que no se desaproveche el valor que a la función analizada puede añadir este derecho. En relación con su ejercicio, obvio es resaltar que desde su vertiente de control cobrará especial significado su ejercicio por parte de personas jurídicas y colectivos sociales. Para los mismos, el derecho de petición, en una interpretación suficientemente amplia del mismo, puede convertirse en un poderoso instrumento de control del gobierno a través de la sede parlamentaria ${ }^{26}$.

Un instrumento al que necesariamente ha de aludirse, como excepción a la consciente omisión de los denominados clásicos instrumentos de control, es la comisión de investigación. Se trata del instrumento al que más atención ha dedicado en los últimos años la doctrina y la opinión pública. Esto no puede extrañar si se considera que, dentro del actual repertorio a disposición del Parlamento para ejercer y hacer visible su función de control, la investigación mediante la creación de la correspondiente comisión resulta el mecanismo más poderoso y, sobre todo, aquél que ofrece un mayor potencial. Sin embargo, a nadie escapa que su actual regulación, totalmente dependiente de las reglas de juego marcadas para la dialéctica mayoría/minoría, ha desvirtuado seriamente su naturaleza y debilitado gran parte de sus posibilidades. La capacidad de decisión que indefectiblemente ejerce la mayoría ha provocado esta situación. Especial importancia tiene el hecho de que esa situación no sólo se extiende al momento de su creación sino que, lo que resulta más im-

26 Sobre la consideración del derecho de petición como instrumento de control, puede verse, E. GUIRÓN REGUERA, La revitalización del derecho fundamental de petición por la nueva regulación legal, RVAP n. ${ }^{\circ}$ 62, 2002; A. MONTIEL MÁRQUEZ, El derecho de petición: ¿instrumento de participación directa de los ciudadanos o manifestación de la función de control?, Cuadernos Constitucionales de la Cátedra Fadrique Furió Ceriol 30/31, Valencia, 2000. Un comentario sobre la Ley Orgánica 4/2001, I. FERNÁNDEZ SARASOLA, Comentario a la Ley 4/2001 reguladora del derecho de petición, REDC n. ${ }^{\circ}$ 65, 2002. En este trabajo, como se tendrá ocasión de exponer en páginas posteriores, se defiende que el derecho de petición vinculado a la Institución parlamentaria se traduzca en un específico derecho a la información y participación parlamentaria. 
portante, a su funcionamiento. Todo el trabajo cotidiano de la comisión se supedita al citado criterio restringiendo, lógicamente, su eficacia como instrumento de control. A ello hay que sumar las lógicas y necesarias limitaciones que afectan a su funcionamiento en el momento en que también resulta afectada la acción de la justicia.

A pesar de todo, no puede desconocerse que sigue siendo uno de los principales medios de ejercicio de la función de control. El mero hecho de solicitar su creación provoca un debate que es control y la negativa suele tener un coste político. Además, una vez creada una comisión su discurrir es difícil de dirigir en términos absolutos, pudiendo siempre suceder acontecimientos ingratos para la mayoría y para el Gobierno. O para quien haya puesto en marcha la comisión, si de sus trabajos se deriva con nitidez que no existía base real para la correspondiente denuncia política. Además, siempre provoca un debate con las correspondientes comparecencias, pruebas documentales, que suponen un ejercicio constante de control, especialmente significativo por la audiencia que los medios suelen otorgar a estas comisiones ${ }^{27}$.

Sin duda, se trata de un instrumento complejo que se enfrenta a una problemática que supera su propia dimensión como expresión de la función de control atribuida al Parlamento. Por ello, los cambios que puedan plantearse deben ser fruto de una reflexión serena. Ahora bien, existe margen para equilibrar las posiciones de la mayoría y de la minoría de manera que, en paralelo, se incremente su eficacia. Junto a ello, su reconstrucción también habrá de ir ligada a un incremento de la disponibilidad de medios que favorezca una autonomía real en su funcionamiento. En cualquier caso, la reflexión deberá realizarse desde un realismo que contribuya a evitar su utilización sin fundamento o su colisión con la actuación judicial. La eficacia de un instrumento como el analizado, de tanta transcendencia social, pasa por la prudencia en su utilización y por la limitación de sus objetivos a la esfera meramente política.

Comentario singularizado merece el papel del debate parlamentario en relación con el control. Con el debate y, sobre todo, con su recepción por los ciudadanos, no sólo se articulan los mecanismos necesarios para facilitar la conformación de la opinión pública, lo cual es, por si mismo, de gran importancia, sino que se fortalece y favorece el control del poder político. Vinculado a la idea de publicidad, el debate es control. La discusión pública en el Parlamento transciende el funcionamiento de las cámaras para constituirse en auténtica garantía de libertad. Desde esta dimensión, va a constituir la expresión del Parlamento como espacio de la competencia política y del pluralismo. La significación del debate, singularmente considerado, como una de las herramientas

27 La bibliografía sobre la comisión de investigación es muy amplia. Por todos, y con amplia bibliografía, I. ASTARLOA HUARTE-MENDICOA y M. CAVERO GÓMEZ, Comisiones de investigación, en la obra colectiva dirigida por O. ALZAGA VILLAMIL, Comentarios a la Constitución española de 1978, Tomo VI, Cortes Generales-Edersa, pp. 569-664; A. ARÉVALO, Reflexiones sobre las comisiones de investigación o encuestas parlamentarias en el ordenamiento constitucional español, RCG n. ${ }^{\circ} 11,1987$. 
de mayor importancia para el ejercicio del control, hace preciso un examen en profundidad de la práctica existente. De acuerdo con la misma, la posición de primacía del Gobierno, incluso de los grupos parlamentarios de la mayoría es muy relevante. Este modelo, más que privilegiar la función de control, la erosiona. Como muestra de ello, baste recordar que, siempre y en cualquier lugar, el cierre del debate corresponde bien al Gobierno bien a los grupos de la mayoría o la posición de privilegio que los miembros del ejecutivo poseen en relación con la utilización del turno de palabra. Si al menos no en todas las ocasiones correspondiese al Gobierno cerrar el debate, la situación ya cambiaría algo. Sólo con la adopción de dos o tres medidas de esta índole, los debates cobrarían mayor viveza y servirían mejor al control parlamentario ${ }^{28}$.

Otra dimensión desde la que es necesario analizar la relación del debate con el control es la de su traslación a la sociedad, es decir la articulación de un procedimiento que por su agilidad pueda interesar a la sociedad y, por ende, a los medios de comunicación que, de esta forma se verían obligados a dar mayor presencia a la vida parlamentaria. La experiencia demuestra que el Parlamento puede interesar a la sociedad. De hecho, los debates sobre el estado de la Nación, las preguntas al Presidente del Gobierno o determinadas comisiones de investigación, han tenido un seguimiento bastante elevado. El incremento de la audiencia es siempre incremento del control. Del control del Parlamento al ejecutivo pero también del control de la sociedad al sistema político. Es cierto que en muchas ocasiones el interés viene dado por el tema. Pero siendo eso incuestionable, también lo es que procedimientos de debate más ágiles, más propensos a buenos cruces dialécticos, favorecerían significativamente su audiencia y, con ella, el control.

Materia a la que no puede ser ajeno el examen de la función de control es la existencia de medios de comunicación públicos, singularmente de televisiones. Las televisiones públicas deben ser objeto de una especial atención por parte del Parlamento. Su importancia obliga a establecer mecanismos de control de su gestión que vayan más allá de los actualmente existentes, como son las comisiones dedicadas específicamente a esta cuestión. Tampoco es suficiente el modelo de gestión por Consejos Audiovisuales, vigente en algunos territorios El Parlamento, como expresión inequívoca del pluralismo político, debería participar directamente en la gestión de la programación de las televisiones públicas, al menos en lo relativo a su programación de informativos. De hecho, y teniendo presente la existencia de un cada vez más elevado número de televisiones privadas, la existencia de canales públicos sólo se justifica por una programación que prime la calidad y una información plural en donde todas las sensibilidades políticas se encuentren en igualdad de oportunidades. Las

28 En este sentido, A.M. ABELLÁN GARCÍA GONZÁLEZ, El Parlamento como órgano de expresión de la opinión pública: la publicidad parlamentaria frente al secreto, RCG n. ${ }^{\circ}$ 18, 1989, p. 200; I. MOLAS i BATLLORI, La oposición parlamentaria en el siglo XXI en El Parlamento del siglo XXI, ob. cit., pp. 74-75; J. J. SOLOZABAL ECHAVARRÍA, Opinión pública y Estado constitucional, Derecho privado y Constitución n. ${ }^{\circ} 10,1996$. 
televisiones públicas debieran tener como razón de ser asegurar esa pluralidad informativa y al Parlamento le corresponde asegurarse de que la misma es una realidad. Ésta es una de esas funciones que claramente le corresponde si se le entiende como garante de la pluralidad social.

Los instrumentos enumerados no agotan la posible emergencia de nuevas manifestaciones de control. Un examen generalizado de esta cuestión daría como resultado fórmulas novedosas que de seguro enriquecerían la visión que actualmente emana de los reglamentos parlamentarios. De esta manera, lo más importante es abrir esa discusión y hacerlo desde el presupuesto de que las fronteras tradicionales no delimitan nada. Junto al desarrollo de nuevas figuras, desde luego, también habría que pensar en el reforzamiento de las existentes, modificando, en algunos casos de manera sustancial, las reglas que rigen a los mismos. Y, por supuesto, también debería prestarse atención a las circunstancias materiales en las que la oposición desarrolla su trabajo. Normalmente, la distribución de medios entre los distintos grupos parlamentarios no tiene en consideración el hecho de que buena parte del trabajo de los grupos del Gobierno es realizado desde los departamentos ministeriales. De esta forma, el desequilibrio de medios entre mayoría y minoría es escandaloso. De nuevo, un amplio camino se ofrece para la búsqueda de fórmulas más equilibradas, de forma que la oposición pueda alcanzar mayor efectividad en el ejercicio de su función constitucional de control ${ }^{29}$.

Junto a los instrumentos de control en sede parlamentaria, es preciso hacer referencia a las garantías relacionadas con su ejercicio y efectividad. Sin ellas, los instrumentos de control, como los derechos, se pierden en un limbo biensonante.

Desde esta perspectiva, la primera cuestión que debe ser examinada es la relativa a la garantía jurisdiccional del ejercicio de la función de control. Como es sabido, al considerarse que el ejercicio de los derechos propios de los diputados forman parte de su ius officium y, desde el mismo, del derecho constitucionalmente protegido a la participación política, en la actualidad, las posibles vulneraciones de estos derechos por los órganos rectores de las cámaras son susceptibles de amparo ante el Tribunal Constitucional. La finalidad de este régimen no es otra que la de intentar garantizar una protección eficaz de un derecho fundamental. De un derecho que, por lo demás, y como sucede a la libertad de expresión, tiene una transcendencia especialmente significativa ya que desborda con amplitud el ámbito de lo meramente subjetivo para proyectarse sobre toda la comunidad.

Mas el citado régimen de protección no es todo lo eficaz que debiera. El excesivo lapsus de tiempo que transcurre entre el acto parlamentario y la sen-

29 Así, por ejemplo, Schneider plantea como posibles medidas para fortalecer la función de control, las siguientes: a) que los lideres de la oposición puedan intervenir en cualquier momento; b) la creación de un servicio específico de la oposición orientado hacia la crítica, el control, y la formulación de alternativas; c) partidas específicas en los presupuestos para la oposición; d) reglamentar los términos oposición, líder de la oposición, grupos de oposición y derechos de oposición (J.P. SCHNEIDER, Democracia y Constitución, CEC, 2001). 
tencia del Tribunal reduce hasta casi lo simbólico el valor de este régimen de protección. La significación de este retraso no descansa, básicamente, en la no recepción de la documentación pedida o en la no tramitación de la pregunta no calificada sino en la impunidad que otorga al ejecutivo y a la mayoría parlamentaria. Conociendo de la lentitud en la respuesta, el riesgo político de una negativa no justificada es mínimo. Por ello, no habría que desdeñar la posibilidad de reforzar las garantías jurisdiccionales sobre las distintas manifestaciones del ejercicio de la función de control. Así, cabría articular un procedimiento especial que garantice la celeridad en la resolución de la demanda. Se trataría de articular un procedimiento sumario, riguroso en el trámite de admisión. Su importancia no sólo radicaría en el reforzamiento que a posteriori supondría para el ejercicio de la función de control sino en los efectos que tendría su mera existencia. Conocedora de que en plazo breve podría existir una sentencia contraria, la mayoría sería más cauta a la hora de adoptar determinadas decisiones.

La protección jurisdiccional no es la única garantía que exige la función de control. Hay que insistir en que el control que no se difunde no existe. El control parlamentario, como se dijo, tiene como condición la recepción social. Sólo si existe esa recepción, el Gobierno puede ser sancionado o verse compelido a no hacer una cosa determinada. La conclusión no puede ser sino la obligación de los parlamentos de fortalecer los instrumentos de difusión de las acciones parlamentarias de control. Ello significa, entre otras cosas, informar a los ciudadanos de las distintas maneras de difusión de ese control y de las formas a través de las cuales pueden realizar su seguimiento. Es preciso hacer pedagogía, explicar la manera de hacer control y la manera de acceder al mismo. Alguien puede alegar que ésta es tarea que corresponde a los medios de comunicación. Sin duda, éstos ejercen esta función y no sólo deben seguir haciéndolo sino que el Parlamento debe procurar reforzar el seguimiento que de la misma realizan. Ahora bien, los criterios de esos medios necesariamente diferirán de los que regirían una posición institucional desde la pluralidad. Además, la tendencia creciente a la concentración monopolística de su propiedad reduce paulatinamente los tradicionales contrapesos en el sector. Por ello, las cámaras no pueden dejar exclusivamente en sus manos la difusión de la acción de control $^{30}$. A la realización de esta tarea debería servir la televisión pública y el control que sobre sus contenidos se tenga desde el Parlamento. Junto a ello, Internet, convenientemente utilizado y divulgado, se muestra como instrumento de especial utilidad en esta tarea. La difusión de las diferentes prácticas del control parlamentario debe entenderse integrado en la propia función de control.

La eficacia y la difusión del control son temas esenciales al moderno Parlamento. Casi puede decirse que éste es el verdadero núcleo del debate, por en-

30 En este sentido, P. MAMBREY, H-P. NEUMANN y K. SIEVERDINGBECK, Bridgin the Gap between Parliament and Citizan-the Internet services of the German Bundestag en Parliamentary Affairs, Vol. 52, n. ${ }^{\circ} 3,1999$, p. 491. 
cima, incluso, del análisis y regulación de los distintos instrumentos que han de servir a esta función. Las posibilidades que al respecto tiene el Parlamento contemporáneo son grandes, inimaginables hasta fechas muy recientes. Hoy se trata exclusivamente de voluntad política. No existe otro obstáculo. Para vencer los naturales recelos de la mayoría no hay argumento más convincente que insistir en la idea de que el Gobierno de hoy será la oposición de mañana. Las decisiones que se adopten en relación con el fortalecimiento del control a ejercer por la oposición no benefician a unos u a otros sino al sistema en su conjunto y desde esta perspectiva debieran ser examinadas.

\section{LA RESPONSABILIDAD DEL GOBIERNO EN SEDE PARLAMENTARIA}

Si bien control y responsabilidad política son dos conceptos formalmente diferenciados, no parece posible una separación material nítida entre ellos. Como se indicó, los instrumentos específicos de responsabilidad política en sede parlamentaria son también instrumentos de control, y muchas veces tan sólo eso, instrumentos de control. Por ello, el análisis del presente de esta función exige una parada, siquiera breve en la idea de responsabilidad.

En los últimos años, la doctrina ha mostrado un interés significativo por la responsabilidad política o rendición de cuentas. La rendición de cuentas del sistema político no se limita a la relación entre Parlamento y ejecutivo aunque, sin duda, sea ésta uno de sus núcleos. Como se señaló, la existencia de una sanción efectiva, normalmente en forma de remoción, es lo que diferencia a la responsabilidad del control en sede parlamentaria. En cualquier caso, hay que recordar que los instrumentos de responsabilidad lo son también de control. Es más, normalmente sólo ejercen desde esa dimensión. Los citados instrumentos se ponen en marcha por los grupos de oposición con la única finalidad de desgastar al Gobierno, en la conciencia de que no cuentan con los apoyos suficientes para sacarlos adelante.

La activación de los mecanismos de rendición de cuenta por parte del Parlamento sería una respuesta a la ruptura del equilibrio inicial de confianza que hizo posible el acceso del Gobierno al poder. Un Gobierno sería coherente con la filosofía de responsabilidad mientras no existiese razón para que se le derribase. En el momento en que surgiese esa razón, el equilibrio inicial debería entenderse como roto y, por tanto, los mecanismos parlamentarios de responsabilidad, deberían activarse. La confianza se otorga sobre unos parámetros cuya ruptura puede considerarse objetivable, al menos en sus rasgos más generales ${ }^{31}$.

Los instrumentos parlamentarios de rendición de cuentas, tal y como se encuentran diseñados en la actualidad, en el contexto del llamado parlamenta-

$31 \mathrm{Al}$ respecto, M. LAVER y K. A. SHEPSLE, Government Accountability in parliamentary democracy en Democracy, Accountability and Representation, Cambridge, 1999, p. 291. 
rismo racionalizado, son escasamente eficaces. A nadie se le oculta que la extensión del citado modelo ha venido acompañada por un debilitamiento muy significativo de los instrumentos de responsabilidad en sede parlamentaria. Ello, coinciden casi todos los analistas, es una de las causas más importantes del debilitamiento de la Institución parlamentaria. En correspondencia con esta nota, los gobiernos suelen estar en disposición de controlar la agenda parlamentaria en relación con estos instrumentos a través de los grupos parlamentarios de la mayoría. Esto puede explicar tanto el renovado interés por esta institución como el hecho de que tradicionalmente los esfuerzos teóricos se hayan centrado en el estudio genérico de la categoría del control parlamentario ${ }^{32}$.

Desde su inserción en un régimen parlamentario en el que el valor de la estabilidad del Gobierno posee una importancia no puesta en cuestión, el funcionamiento de los instrumentos de responsabilidad política en el Parlamento es complicado. Por ello, quizá sea una deriva necesaria la consideración global de la rendición de cuentas del sistema político en su conjunto, centrando el papel del Parlamento en lo que de forma estricta se ha denominado control. Ahora bien, a la Institución parlamentaria le continua correspondiendo un papel protagonista en esa rendición de cuentas, aunque sólo sea como escenario de sus expresiones más emblemáticas. Por otra parte, nada impide reflexionar sobre posibles medidas que permitiesen profundizar en la misma en sede parlamentaria. Entre la situación actual y la entrega al Parlamento de un poder ilimitado sobre la estabilidad del Gobierno, existe un largo espectro de posibilidades. Así, por poner un ejemplo, parece fuera de toda duda que con un procedimiento debidamente aquilatado podrían establecerse mecanismos de sanción efectiva singularizados para ministros u otros altos cargos. Esta responsabilidad individual, claramente delimitable en numerosas ocasiones, no plantea problemas significativos de estabilidad. Más bien, al revés. La existencia de estos procedimientos podría ser un dique efectivo frente a aventuras singulares y evitar a los gobiernos desgastes inútiles cuando se instala la contumacia de la continuidad. Desde luego, por el conjunto de la ciudadanía sería percibido como una medida de salud del ejercicio de la política.

Como se ha repetido, no debe perderse de vista la consideración de la naturaleza de control en sentido estricto que también poseen estos instrumentos cuando son utilizados con la intención de desgastar al ejecutivo. Ello sirve para llamar la atención sobre los aspectos procedimentales de los mismos, esenciales para que, al menos, puedan servir al citado control. En efecto, junto

32 La bibliografía sobre los instrumentos de rendición de cuentas es muy escasa desde el análisis jurídico y más todavía desde otras perspectivas como la de la ciencia política o de la sociología. Todavía más sorprendente resulta el escaso espacio que se dedica al papel que a la Institución parlamentaria le corresponde en el juego global de la accountability. Al respecto, véase M. LAVER y K. A. SHEPSLE, Government Accountability in parliamentary democracy, ob. cit., pp. 290-296. Sobre la operatividad de los mecanismos de responsabilidad parlamentaria, E. GUERRERO SALOM, Crisis y cambios en las relaciones Parlamento-Gobierno (1993-1996), Tecnos, 2000, pp. 257-342. Sobre el origen y evolución de la noción de responsabilidad política, J. M. DÍAZ MARTíN, La responsabilidad política en los sistemas democráticos, Cortes Valencianas, 2001. 
a la creación de algún instituto nuevo de responsabilidad, hay que propugnar un estudio y revisión de los procedimientos vigentes encaminado a reforzar la posición de las minorías en los mismos. Si al hecho de que los criterios de adopción de la decisión están claramente al servicio de la mayoría, se une un procedimiento que en muchas ocasiones desgasta más a la oposición que al Gobierno, el resultado no puede ser otro que el que es, la difuminación casi radical de los instrumentos de responsabilidad política en sede parlamentaria.

Los procesos y demandantes de esa responsabilidad se han multiplicado, con un protagonismo singular de los medios de comunicación social. De algún modo, en esta generalización de sujetos y procedimientos se encuentra la raíz de la crisis de la responsabilidad. Reclamar el protagonismo del Parlamento en esta materia, buscar, si no la exclusividad, sí, al menos, un lugar de privilegio incontestable, no sólo tiene como objetivo fortalecer la posición social e institucional de las cámaras sino también contribuir a fortalecer la responsabilidad. El Parlamento debe ser cauce de agregación de los diferentes procesos de responsabilidad, suma y fin de un concepto en el que, en gran medida, confluye la concepción política de la democracia parlamentaria. Precisamente, esta importancia, su significación en el conjunto del sistema, obliga a buscar respaldo constitucional para la reconstrucción de este instituto.

\section{LAS FRONTERAS DEL CONTROL PARLAMENTARIO. CONTROL Y NUEVAS TECNOLOGÍAS}

En las líneas que siguen, se hará referencia a las barreras que en la actualidad tiene la función y a algunos de los instrumentos a su disposición para superarlas. El Parlamento puede disponer de medios técnicos muy relevantes para ejercer esta función y, en consonancia, superar alguno de los obstáculos tradicionales. Pero, junto a ello, como se vio, la evolución social enfrenta a la Institución a obstáculos hasta ahora desconocidos como pueden ser la difuminación de la relación entre el poder y el territorio o la disolución de las tradicionales diferencias entre lo público y lo privado. Son cuestiones que merecen un comentario singularizado para poder tener una visión más completa de esta función.

El fortalecimiento y renovación del Parlamento pasa por la eliminación o debilitamiento de esas barreras. La incorporación de las nuevas tecnologías ha contribuido ya a suprimir o paliar alguna de las dificultades tradicionales y es de esperar que en el futuro otorguen nuevas posibilidades. Ahora bien, hay que dejar constancia de que no se trata tan sólo de barreras tecnológicas, de dificultades materiales para el desarrollo de esta función. Hay también barreras ideológicas y premisas clásicas del trabajo parlamentario que, si en otras épocas tuvieron sentido, hoy han perdido gran parte del mismo, sobre todo si se tiene en consideración la importancia de los cambios acaecidos en los últimos años. En este marco es el que hay que situar la necesidad de extender el control parlamentario, aun en sus expresiones más tibias, a nuevos ámbitos como pueden 
ser algunas manifestaciones del actuar privado que en nuestros días poseen una extraordinaria incidencia sobre la vida de la comunidad.

Desde las posibilidades que el citado desarrollo tecnológico ofrece, algunas ya firmes y consolidadas otras en estado embrionario, el Parlamento debe reaccionar y extender su actividad de control de manera universal. Es función primigenia de las cámaras garantizar que no existan zonas de actuación del poder ejecutivo exentas de control. La importancia de este reto es singular. Sin duda, una de las características de la época de transición en la que se desenvuelve el Estado contemporáneo es la indefinición del poder público. La necesidad de adoptar formas más ágiles de gestión, la globalización de la economía y las tensiones transnacionales e intranacionales a las que se ve sometido el poder estatal, han provocado serías dudas sobre la propia definición de lo público y sobre el lugar mismo que al poder público corresponde ostentar en la dirección y ordenación del nuevo modelo social. Sea cuál sea el devenir, el Parlamento no debe ser ajeno a su definición. Y, desde luego, en ningún caso debe abandonar la posición que le corresponde como principal instrumento político de control. El Parlamento no puede olvidar que su renuncia sería la de toda la sociedad. De esta forma, si un nuevo modelo social obliga no sólo a extender el control a entes y organizaciones públicas escondidas bajo paraguas de Derecho privado sino también a grandes organizaciones privadas que ejercen funciones transcendentales para el adecuado funcionamiento de la sociedad, no deberá tener empacho en hacerlo, aunque pueda resultar inicialmente extraño.

Si se hace referencia a las zonas de poder exentas del necesario control parlamentario, hay que realizar cita expresa de la construcción europea. Ni el proceso de transferencia de poder ni su ejercicio han tenido ni tienen el debido control parlamentario. La transformación que en los criterios tradicionales de ejercicio del poder ha supuesto la Unión Europea ha sido formidable. Por sí sólo, este proceso debería haber obligado a un replanteamiento del trabajo de los parlamentos nacionales y de la Institución globalmente considerada. Ello no ha sucedido. Los pasos dados al respecto sólo pueden ser definidos como insuficientes. Lo cierto es que desde la actual estructura parlamentaria y desde la vigente manera de entender las relaciones interparlamentarias no es fácil obtener éxito en tarea tan ardua. Puede decirse, pues, que un proceso de tanta significación política y tan extraño a los cánones tradicionales como el de la construcción europea, lo que hace es precipitar la tarea de renovación de la Institución parlamentaria. La distinta conformación del poder, producto de empresas como la Unión Europea o de fenómenos complejos como los englobados bajo la idea de globalización, exige que los parlamentos adapten su funcionamiento a los mismos. Si el poder se diluye en distintas instancias, su control requerirá de una colaboración efectiva entre los distintos parlamentos implicados ${ }^{33}$.

33 La ajenidad del Parlamento para con el proceso de construcción europea, ha sido subrayada por el profesor Chrestia (P. CHRESTIA, La rénovation du Parlement, une oeuvre inachevée, ob. cit., p. 315). Sobre los problemas que para la democracia plantea la construcción europea, puede verse, entre otros, R. DAHRENDORF, Después de la democracia, ob. cit., pp. 39-44. 
Si el desarrollo del modelo político representado por la Unión Europea es buen ejemplo de las dificultades que para el ejercicio de la función de control por los parlamentos nacionales plantean las nuevas relaciones del poder con el territorio, la consolidación de la propiedad y formas jurídicas privadas en relación con sectores estratégicos para la colectividad es ejemplo paradigmático de cómo las transformaciones sociales están subvirtiendo los presupuestos clásicos del control ${ }^{34}$. Ello unido al presupuesto clásico de que el Parlamento sólo ha de ejercer el control en relación con entidades públicas ha tenido como consecuencia la emergencia de zonas extensas exentas de control parlamentario, lo que bien puede denominarse huida del control parlamentario.

La perdida de la consideración pública de actividades o servicios como las telecomunicaciones o la producción de energía eléctrica serían manifestaciones de lo indicado. Junto a ello, la concurrencia de agentes privados en actividades no sólo públicas sino ligadas al núcleo de lo que tradicionalmente ha definido al Estado, como es la seguridad, acrecienta significativamente la importancia del fenómeno descrito. No sólo el Parlamento pierde control sobre el ejercicio de actividades esenciales, hasta hace muy poco consideradas públicas y sobre las que, en consecuencia, ejercía el correspondiente control, sino que, además, con los distintos procesos privatizadores ha perdido fuentes de información de gran importancia. En conjunto, pues, la función de control ha resultado seriamente deteriorada.

Hasta la fecha, el Parlamento no ha estado atento a este fenómeno ${ }^{35}$. No se ha planteado el debate exigible. Sin embargo, la dimensión del cambio es extraordinaria. La generalización de las privatizaciones de las empresas que prestaban servicios del máximo interés público, la redefinición del concepto de servicio público, la presencia del sector privado en las zonas de definición pública, transcienden un mero problema de competencias. Detrás de todo ello hay una innegable transformación del Estado, del concepto de lo público. Ello habría debido provocar en el Parlamento una reflexión sobre su papel en el nuevo modelo de Estado y los cambios a plantear para adecuarse a las nuevas exigencias. Pero no se ha hecho. No se trata de un prurito institucional, de rescatar al Parlamento, de reforzar sus poderes. Se trata de asegurar a la comunidad la existencia de un órgano que desde la pluralidad vele por la adecuada prestación de servicios que siguen siendo del máximo interés, de un órgano que impida los excesos que pudieran cometerse y frente a los cuales el Gobierno pue-

34 En este sentido puede verse, E. W. BÖCKENFÖRDE, Estudios sobre el Estado de derecho y la democracia, ob. cit., p. 42; L. AGUIAR de LUQUE, La problemática del control en la actualidad en El Parlamento a debate, ob. cit, p. 87.

35 Sobre este extremo, J. ALFONSO GIL, Notas sobre la nacionalización y el control parlamentario de la empresa pública (experiencias en nuestro entorno), Hacienda Pública Española n. ${ }^{\circ}$ 89, 1984. En relación con las denominadas agencias independientes, junto al control genérico a las que las mismas se deben, se ha planteado en sus respectivas leyes de creación procedimientos específicos de control (F. VALLESPIN, Un nuevo espacio público: la democracia mediática, en Teoría politica: poder, moral y democracia, Alianza, 2003, p. 123). 
de estar en situación de debilidad. Se trata, también, de garantizar la necesaria información y transparencia sobre el presente y futuro de esas actividades.

Para realizar esta tarea, como se señaló, habrá de superarse la tradicional definición del ámbito subjetivo del control. Seguramente, deberá pensarse en cambiar el criterio subjetivo por un criterio objetivo conectado a la idea de interés general. Lógicamente, la propiedad privada y las normas de Derecho privado obligarán a establecer determinadas cautelas y límites al alcance del control en relación con los mismos. No será una tarea sencilla. Pero es imprescindible acometerla. Si no se realiza, quedarán fuera del control parlamentario materias de extraordinaria importancia. La consecuencia sería negativa para la comunidad y para la credibilidad del Parlamento.

Pero junto a las nuevas negativas, también las hay positivas. En un momento tan significativo, la tecnología viene en ayuda de la Institución. Su importancia es general y horizontal. Toda la actividad parlamentaria de control puede quedar transformada por el desarrollo tecnológico. La primera reflexión debe realizarse en relación con la información. Como se dijo, esas tecnologías, especialmente Internet, han supuesto la eliminación de cualquier barrera en relación con el acceso a la información ${ }^{36}$. Es éste un dato fundamental para abordar el control en el Parlamento contemporáneo. La mera posibilidad de poder disponer de la información que se desee ha de entenderse como un formidable contrapoder en manos del Parlamento y, por tanto, como un instrumento de control de primer orden. Y hay que hacer notar que aunque Internet se presenta como protagonista de la información en el nuevo Parlamento, no va a ser el único instrumento que las nuevas tecnologías ponen a disposición del mismo. Así, el desarrollo de programas informáticos puede hacer viable el acceso directo a información de gran importancia para el ejercicio de su función de control.

Especial significación posee el desarrollo de los instrumentos informáticos en relación con el control de la ejecución presupuestaria. Siendo ésta una cuestión fundamental del control político, saber en qué se gasta el dinero el Gobierno, cómo cumple con el presupuesto que se le autorizó, lo cierto es que los parlamentarios han renunciado de hecho a su ejercicio. Y es que con los medios a disposición de diputados y grupos, realizar esta función es un ejercicio imposible. Pues bien, la informática altera notablemente esta situación. Además de posibilitar el acceso a información hasta ahora indisponible para los diputados, permite su tratamiento de forma que se pueda trabajar sobre datos manejables y no sobre suma de cifras y cifras inconexas. Con su desarrollo, las hasta ahora inviables oficinas de control presupuestario pueden ser una realidad de

36 Algunos autores plantean como las nuevas tecnologías pueden ser también un instrumento de control de la acción política en manos de los ciudadanos, destacando como la información en la red puede contribuir eficazmente a ello, M. PÉREZ-UGENA y A. PÉREZ-UGENA, Implicaciones constitucionales de las nuevas tecnologias, RDP n. ${ }^{\circ}$ 54, 2002, p. 189; M. CARTER, Speaking Up in the Internet Age: Useand Value of Constituent E-mail and Congressional Web-sites, Parlamentary Affairs, Vol. 52, n. ${ }^{\circ}$ 3, 1999, pp. 464-480. 
gran utilidad para el cumplimiento de las funciones parlamentarias, especialmente las relacionadas con el presupuesto y su control. De hecho, puede decirse que se trata de una oportunidad única para resucitar una parte fundamental del trabajo parlamentario que hace tiempo descansa plácidamente.

Otro ámbito en el que las nuevas tecnologías pueden suponer un plus notable es el relativo al de la evaluación de las políticas del ejecutivo. La introducción de un control evaluativo, de acuerdo con unos parámetros previamente establecidos, emerge como uno de los futuros instrumentos del control parlamentario. Seguramente, en otro momento histórico, esto no era posible o, en su caso, de coste exagerado. Hoy la tecnología permite articular esta política de control con sencillez y coste reducido. Al Parlamento le corresponderá realizar el preciso esfuerzo organizativo y de imaginación para hacer factible el desarrollo de la citada modalidad de control.

Especial consideración ha de tener esa evaluación en relación con la función legislativa. Hasta la fecha, la relación del Parlamento con las leyes se acaba en el mismo momento de su aprobación. El Parlamento aprueba un texto y puede que ese texto no se cumpla o que no alcance un mínimo de sus objetivos o que quede muy seriamente desvirtuado por su desarrollo reglamentario. Todo ello no puede ser indiferente para la actividad parlamentaria. Una nueva dimensión de la función legislativa exige la incorporación al Parlamento de la labor de control del desarrollo de las leyes. En esta tarea, la informática puede prestar importantes auxilios a diputados y grupos mediante el desarrollo de programas que permitan realizar la correspondiente labor de vigilancia, siendo particularmente significativa para el objetivo de recuperación del significado y posición política de la ley ${ }^{37}$.

\section{A MODO CONCLUSIÓN}

El Parlamento ha de ocupar una posición de privilegio en el mapa político. Una posición indisolublemente vinculada a su relación con la democracia. Una relación que conlleva la necesidad de reivindicar la identificación del Parlamento con la racionalización y limitación del poder. El Parlamento es democracia y desde esta idea ha de entenderse su posición activa en la transformación de un modelo político para conseguir el perfeccionamiento de la identidad democrática de acuerdo al nuevo contexto social y tecnológico.

Desde esa idea, resulta preciso recordar la vinculación del Parlamento con la libertad, una vinculación ligada esencialmente a su función del control del poder político desde la garantía del pluralismo político. Si el Parlamento como manifestación suprema de ese pluralismo ha sido una de las constantes histó-

37 Sobre la evaluación legislativa como control, A. FIGUEROA LARAUDOGOITIA, La evaluación legislativa como control parlamentario en Parlamento y control del Gobierno, Asociación Española de Letrados de Parlamentos-Tecnos, 1995, pp. 213-239; VV.AA., Contrôle parlementaire et évaluation, La Documentation Française, 1995. 
ricas de la Institución, en la actualidad los valores inherentes al mismo cobran, si cabe, mayor protagonismo. Las diferentes funciones parlamentarias y, singularmente, el control, adquieren gran parte de su razón de ser en la garantía que para el pluralismo supone la Institución parlamentaria. Pero para que el control sea real y, por ende, eficaz, han de producirse cambios. Cambios en los instrumentos mediante los cuales se ejerce y cambios en las reglas que dominan su funcionamiento. La traducción interna de un mayor compromiso con el pluralismo debiera ser la introducción de modificaciones en el juego de mayorías y minorías, al menos en relación con aquellas funciones más ligadas a la libertad, como es, de forma paradigmática, el control. La relativización del peso del criterio de mayoría y una aminoración de las diferencias entre las distintas formaciones políticas es perfectamente compatible con el mantenimiento de valores necesarios como el de la estabilidad política, por lo que sólo las posiciones más reacias a dinámicas de cambio es posible alegar en contra del fortalecimiento del pluralismo en la Institución.

Pero el fortalecimiento de la función de control no ha de lograrse tan sólo con medidas internas a las cámaras. Los ciudadanos no pueden desentenderse, en general, de los avatares de la Institución parlamentaria y en particular del ejercicio de la función de control. Entre otras cosas, porque sin ellos, no hay control ninguno. Los ciudadanos tienen que ser vanguardia de la exigencia de la Institución que los representa y del ejercicio que la misma realice de las funciones que tiene encomendadas. La llamada a un derecho al Parlamento que comprenda verdaderos derechos subjetivos que sirvan al fortalecimiento de la función de control y a la identificación del ciudadano con la política, ha de entenderse como una apelación directa a la conciencia pública. Una llamada que debe tener su respuesta en las sedes parlamentarias y en las sedes de los partidos hasta lograr que el proceso de renovación parlamentaria y su necesaria materialización jurídica vaya tomando cuerpo.

La posición del Parlamento en el modelo político de un futuro no tan lejano depende, básicamente, de dos cuestiones. Por un lado, de su capacidad para encauzar las distintas y nuevas formas de participación social y política. Por otro, y muy ligada a la anterior, de su capacidad de adquirir credibilidad en una función de control que cada día se antoja de mayor relevancia. Obviar esta importancia del control para el futuro paradigma parlamentario puede resultar fatal y arruinar cualquier esfuerzo que se realice para adecuar la Institución a la nueva realidad social.

ABstract. Control is the main function of the modern parliament. In this capacity it is indispensible. However, for a variety of reasons is inefficient exercising this task. The political bodies, the agents to controlled and the very instruments of control have all changed. The rules and regulation remains the same, however. Within these pages these circunstances are analysed and possible changes suggested allowing control to take place more efficiently. 